\title{
Combinatorial Synthesis and Evaluation of Vanadium Oxide Films
}

\author{
Qunjiao Wang ${ }^{a}$ \\ ${ }^{a}$ Key Laboratory for electromagnetic processing of Materials (EPM), Northeastern University, \\ Shenyang 110004, China \\ wang-qunjiao@epm.neu.edu.cn
}

Keywords: thermoelectricity; combinatorial pulsed laser deposition; vanadium oxide; film

\begin{abstract}
Combinatorial technology is a powerful tool for new material exploration. $\mathrm{La}_{1-\mathrm{x}} \mathrm{Ca}_{\mathrm{x}} \mathrm{VO}_{3}$ composition-spread films were fabricated by combinatorial pulsed laser deposition and their thermoelectric properties were evaluated paralelly by the multi-channel thermoelectric measurement system. Concurrent X-ray analysis verified the formation of solid soluted films in the full composition range $(0 \leq x \leq 1)$ as judged from the linear variation of the lattice constants. Growth conditions of $\mathrm{LaVO}_{3}$ films were optimized. Good crystallinity of $\mathrm{LaVO}_{3}$ film was obtained at $800^{\circ} \mathrm{C}$, and the power factor of $0.6 \mu \mathrm{W} / \mathrm{cm} \mathrm{K}^{2}$ was achieved. The effects of oxygen content and the substitutions of $\mathrm{Ca}$ and $\mathrm{Ce}$ ions on TE properties of were also analysed respectively. Large TE properties in vanadium oxide system can be expected with the change of vanadium ion valence from $3+$ to $2+$. In La1-xCexVO3 $(0 \leq \mathrm{x} \leq 1)$ system, Ce ion takes $3+$ although $\mathrm{Ce}^{4+}$ is stable in theory.
\end{abstract}

\section{Introduction}

Combinatorial chemical technology started in drug industries for high throughput discovery of new drugs by the integrated organic synthesis [1] and now it is finding a wide possibility in solid state materials as a powerful tool for optimizing the compositions and fabrication conditions by systematically varying several process parameters[2-6]. A large number of samples (combinatorial library) can be fabricated and evaluated in a single run of experiments. So combinatorial technology is a powerful tool for new material exploration.

Thermoelectric (TE) materials attract much interest for such applications as to heat pumps and power generators. At present, the materials with highest TE performance are intermetallic compounds such as $\mathrm{Bi}_{2} \mathrm{Te}_{3}$ [7-9]. However, their practical application to power generation from the waste heat has been drawn back by many material problems like a low melting point, poor oxidation resistance, and an insufficient conversion efficiency in the typical operating temperature range of the waste heat $\left(300-800^{\circ} \mathrm{C}\right)$. The known material of $\mathrm{NaCo}_{2} \mathrm{O}_{4}$ was recently discovered to be good TE material $[10,11]$ to encourage researchers for exploring new TE materials in metal oxides. They are already in oxidized state and thermally stable, and therefore have the potential to overcome the problems mentioned above[12-15]. The large Seebeck coefficient in $\mathrm{NaCo}_{2} \mathrm{O}_{4}$ is explained by the characteristic degeneracy due to spin and orbital degrees of freedom [16]. Thus, some $3 \mathrm{~d}$ transitionmetal oxides are candidates for new thermoelectric materials. Vanadium oxides possess various interesting properties due to the multivalent nature of vanadium. In general, heavy electron systems generate large thermopower due to the large density of state at the Fermi level. Thus, vanadium oxides are good candidates of highly efficient TE materials. A perovskite vanadate $\mathrm{LaVO}_{3}$ is wellknown as a typical Mott-insulator [17-20]. The substitution of divalent cations for $\mathrm{La}^{3+}$ sites can cause the vanadium cation to change the valence state, leading to the enhancement of TE efficiency by the optimization of the vanadium valence state and the career density.

In this paper, combinatorial pulsed laser deposition (CPLD) was applied to fabricate $\mathrm{La}_{1 \text { - }}$ ${ }_{\mathrm{x}} \mathrm{Ca}_{\mathrm{x}} \mathrm{VO}_{3}$ composition-spread films, and TE properties were evaluated by the multi-channel thermoelectric measurement system. 


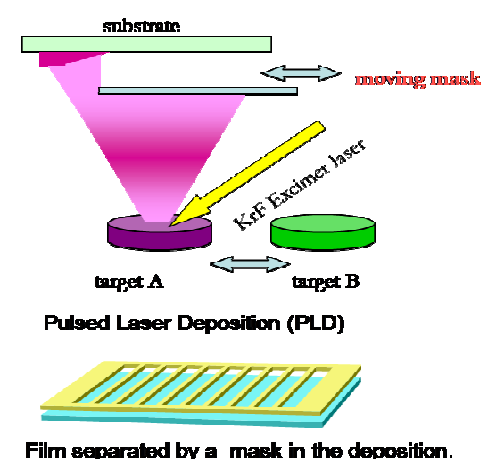

(a)


(b)

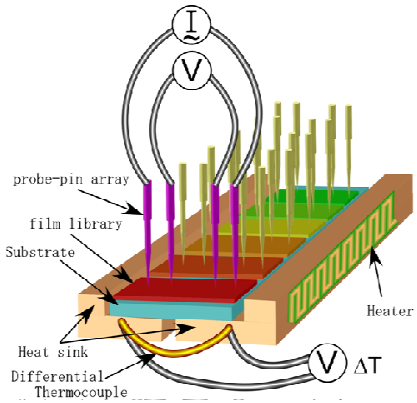

(c)

Fig. 1. Schematic diagram of parallel synthesis system (a) CPLD process (b) Fabrication of composition-spread film (c) The multi-channel thermoelectric measurement system

\section{Experimental}

Combinatorial pulsed laser deposition (CPLD) was developed to fabricate thermoelectric composition-spread films, shown in Fig. 1, which featured a moving mask, a shadow mask, a multitarget holder and a substrate heater. The moving masks were slid during film deposition in synchronization with target exchange and laser conditioning. These operations were controlled by a personal computer installed with LABVIEW program. Target switching and mask motion were


from one unit cell to zero in each cycle of $\mathrm{A}$ and $\mathrm{B}$ film deposition. In this way, the value of $x$ in $\mathrm{A}_{1-}$ ${ }_{x} B_{x}$ was changed linearly from 0 to 1 along one direction of the substrate and this cycle was repeated until the film thickness reached the programmed thickness (Fig. 1(b)). In order to make 10 different strip patterned films, each of which were electrically isolated, the substrate was covered with a pattered shadow mask of Inconel alloy during the deposition (Fig. 1(b)).

$\mathrm{La}_{1-\mathrm{x}} \mathrm{Ca}_{\mathrm{x}} \mathrm{VO}_{3}(0 \leq \mathrm{x} \leq 1)$ composition-spread film library was fabricated on a $\mathrm{SrTiO}_{3}$ substrate with a dimension of $15.0 \times 7.5 \times 1.0 \mathrm{~mm}^{3}$ using a CPLD system illustrated in Fig. 1(a). $\mathrm{LaVO}_{3}$ and $\mathrm{CaVO}_{3}$ targets of $15 \mathrm{~mm}$ in diameter and $5 \mathrm{~mm}$ in thickness were made from stoichiometric $\mathrm{La}_{2} \mathrm{O}_{3}-\mathrm{V}_{2} \mathrm{O}_{5}$, and $\mathrm{CaCO}_{3}-\mathrm{V}_{2} \mathrm{O}_{5}$ mixed powders, respectively. These mixed powders were ground, pressed into pellets, pre-sintered at $600^{\circ} \mathrm{C}$ for $30 \mathrm{~h}$ in air, and sintered at $1000^{\circ} \mathrm{C}$ for $30 \mathrm{~h}$ in air. Although the sintering of bulk perovskite vanadates was conventionally carried out under such a reducing atmosphere as $\mathrm{Ar}$ or $\mathrm{Ar} / \mathrm{H} 2$ mixture, we made the targets by sintering the pellets in air. The $\mathrm{SrTiO}_{3}$ (100) single crystal (cubic, $\mathrm{a}=3.905 \AA$ ) was used as substrate, which has a small mismatch

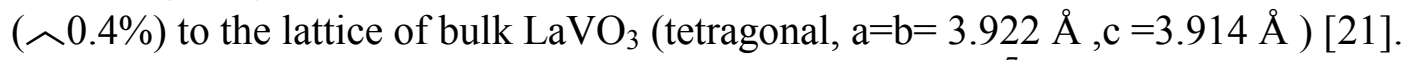

Into the CPLD chamber with a base pressure of $1 \times 10^{-7}$ Torr, Ar-balanced 10 ppm oxygen gas was introduced to regulate a total pressure at $1 \times 10^{-4}$ Torr, i.e. $\mathrm{P}_{\mathrm{O} 2} 1 \times 10^{-9}$ Torr during the film deposition. The substrate temperature during the deposition was varied from 600 to $800^{\circ} \mathrm{C}$. Films were fabricated by the pulsed $\mathrm{KrF}$ excimer laser (Lambda Physik Inc.: COMPex 102, $\lambda=248 \mathrm{~nm}$ ) with an energy density range of $2.5-5.7 \mathrm{~J} / \mathrm{cm}^{2}$ and a laser repetition of $5 \mathrm{~Hz}$. The sintered $\mathrm{LaVO}_{3}$ and $\mathrm{CaVO}_{3}$ targets were alternately positioned at a laser focus to be ablated by the laser pulses as illustrated in Fig. 1(a).

The structure analysis was carried out by conventional X-ray diffractometry (XRD) and 'concurrent X-ray diffractometry' (CXRD) [22,23], which measured XRD spectra of the entire

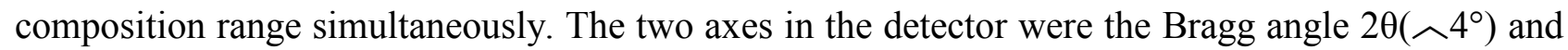
the film position, which directly corresponded to the composition, along the $10 \mathrm{~mm}$ substrate. For the high-throughput evaluation of TE properties of the 10 pieces of film samples simultaneously, a multi-channel thermoelectric measurement system was developed as shown in Fig. 1(c)[24]. This system enabled us to measure the resistivity $(\rho)$ and Seebeck coefficient $(S)$ of the combinatorial film library compared of ten $1.0 \times 7.5 \mathrm{~mm}^{2}$ specimens on a substrate. The power factor $\alpha\left(=\mathrm{S}^{2} / \rho\right)$ was obtained to evaluate thermoelectricity of each film. 


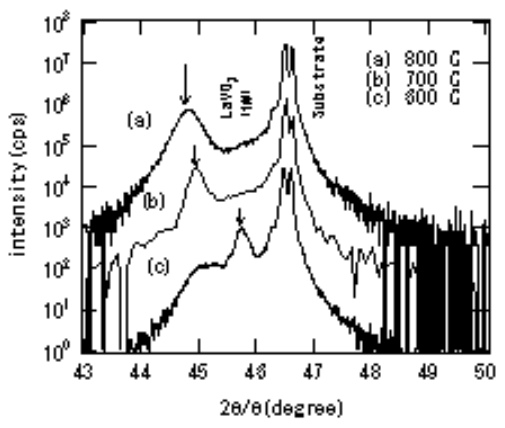

(a)



(b)

Fig. 2. The structures of LaVO3 film grown at different temperatures (a) X-ray diffraction pattern

(b) $C$-axis length

\section{Results and discussions}

In order to obtain good TE properties, the optimum crystal growth condition was investigated. The composition-spread films around $\mathrm{LaVO}_{3}$ were fabricated at different temperatures. Fig.2 (a) shows the XRD patterns of $\mathrm{LaVO}_{3}$ film grown at different temperatures $\left(600-800^{\circ} \mathrm{C}\right)$. The $(001)$ peak of $\mathrm{LaVO}_{3}$ film grown at $800^{\circ} \mathrm{C}$ was very sharp. On the other hand, there was another peak near the (001) peak of $\mathrm{LaVO}_{3}$ film grown at $600^{\circ} \mathrm{C}$, which meant there were two domains in the film grown due to bad crystallinity. Thus at $800^{\circ} \mathrm{C}, \mathrm{LaVO}_{3}$ film with good crystallinity was obtained. $C$-axis length became larger with the enhance of growth temperature, shown in Fig.2(b), which was attributed to the lack of oxygen. So exact formula for $\mathrm{LaVO}_{3}$ film grown at higher temperature should be $\mathrm{LaVO}_{3-\delta}$, which caused the valence of vanadium ion change from $3+$ to $2+$.

Fig. 3 shows the TE properties of $\mathrm{LaVO}_{3}$ films grown at various temperatures. There was little change in the Seebeck coefficients of $\mathrm{LaVO}_{3}$ films grown at different growth temperatures, while the resistivity decreased with the enhance of the growth temperatures. The largest power factor $\left(\alpha=0.6 \mu \mathrm{W} / \mathrm{cm} \mathrm{K}^{2}\right)$ of $\mathrm{LaVO}_{3}$ film was obtained at $800^{\circ} \mathrm{C}$.

Fig. 4 shows a part of CXRD image $\left(21.6^{\circ} \leq 2 \theta \leq 24.1^{\circ}\right)$ for full composition area $(0 \leq x \leq 1)$ of $\left(\mathrm{La}_{1-\mathrm{x}} \mathrm{Ca}_{\mathrm{x}}\right) \mathrm{VO}_{3}$ composition-spread films on a STO substrate. The diffraction angle $2 \theta$ in this image was calibrated by the STO (200) peak positions in order to remove the error due to the substrate setup in the CXRD. It is noted that the CXRD (200) peak in this range was separated into 10 pieces because the films were patterned by a shadow mask as shown in Fig. 1(a). The CXRD peak of the composition-spread films changed linearly, thus indicating that the composition-spread films formed solid solution in the whole composition range $(0 \leq x \leq 1)$. Thus, the c-axis length obeyed Vegard's law. $C$-axis lengths were estimated to be $4.04 \AA\left(\mathrm{LaVO}_{3}\right.$ side $)$ and $3.74 \AA\left(\mathrm{CaVO}_{3}\right.$ side $)$ from the image, respectively. The crystal lattice of $\mathrm{LaVO}_{3}$ films was elongated along the $c$ axis, as the $c$-axis length of $\mathrm{LaVO}_{3}$ films was larger than the data reported for the bulk sample [21]. A compressive strain from the substrate is presumed to elongate the $c$ lattice normal to the substrate.

Fig.5 shows the TE properties of $\mathrm{La}_{1-\mathrm{x}} \mathrm{Ca}_{\mathrm{x}} \mathrm{VO}_{3}(0 \leq \mathrm{x} \leq 1)$ composition-spread films grown at $800^{\circ} \mathrm{C}$. The Seebeck coefficients of $\mathrm{CaVO}_{3}$ side films were close to zero $(0 \sim-5 \mu \mathrm{V} / \mathrm{K})$, while those of $\mathrm{LaVO}_{3}$ side films were large negative values $(\sim-310 \mu \mathrm{V} / \mathrm{K})$. The heavy electron in the Mottinsulator of $\mathrm{LaVO}_{3}$ is considered to cause the large Seebeck coefficient of $\mathrm{LaVO}_{3}$ films [25], while $\mathrm{CaVO}_{3}$ film appears to behave like a normal metal. The substitution of $\mathrm{La}^{3+}$ ions with $\mathrm{Ca}^{2+}$ ions made the valence of vanadium ion change from $3+$ to $4+$, which was responsible for the change of TE properties. The transition point from large negative value to almost zero is around $\mathrm{x}=0.2$, where the metal-insulator transitions was reported to occur [19], so resistivity of $\mathrm{La}_{1-\mathrm{x}} \mathrm{Ca}_{\mathrm{x}} \mathrm{VO}_{3}$ films decreased monotonically from $\mathrm{x}=0.2$ to $\mathrm{x}=1.0$. 


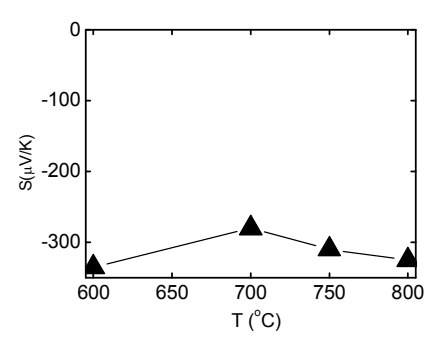

(a)

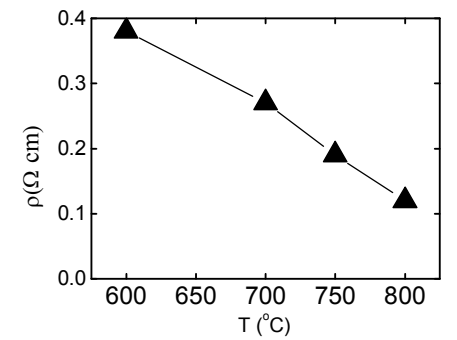

(b)



(c)

Fig. 3. TE properties of LaVO3 film grown at different temperatures (a) Seebeck coefficient :S

(b)resistivity: $\rho$ (c) power factorpower factor : $\alpha(=\mathrm{S} 2 / \rho)$

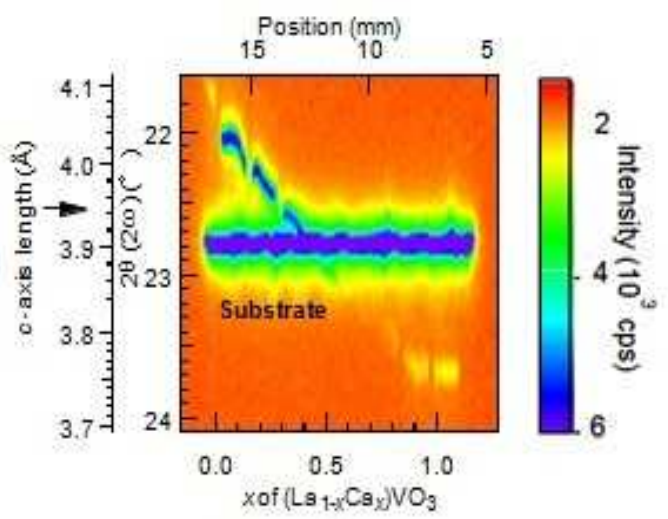

Fig. 4. Concurrent X-ray diffraction image of La1-xCaxVO3 $(0 \leq x \leq 1)$ composition-spread films on SrTiO3 substrate



(a)

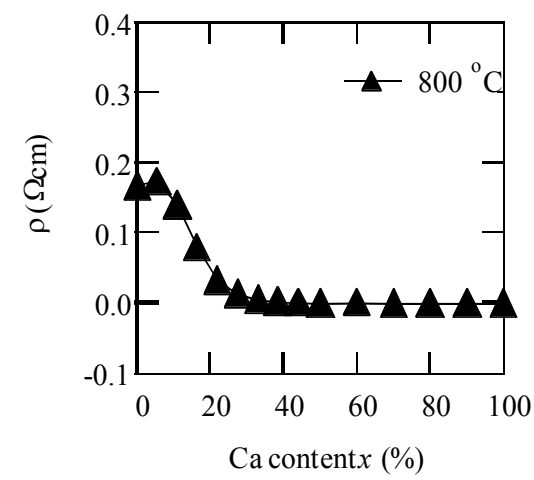

(b)

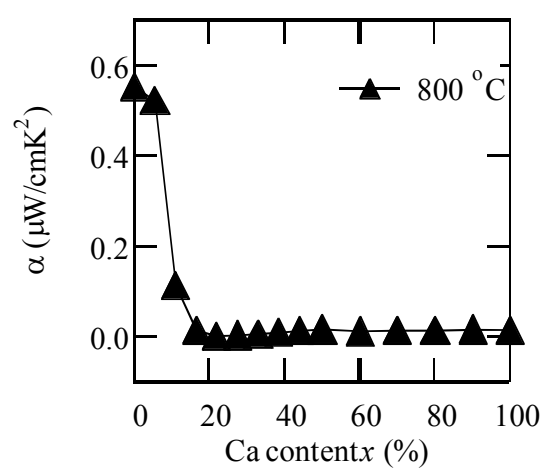

(c)

Fig. 5. TE properties of La1-xCaxVO3 $(0 \leq x \leq 1)$ composition-spread films. (a) Seebeck coefficient :S (b)resistivity: $\rho$ (c) power factorpower factor : $\alpha(=\mathrm{S} 2 / \rho)$

The Seebeck coefficient of $\mathrm{La}_{1-\mathrm{x}} \mathrm{Ca}_{\mathrm{x}} \mathrm{VO}_{3}$ close to $\mathrm{CaVO}_{3}(0.6 \leq \mathrm{x} \leq 1.0)$ was reported to be sensitive to the temperature and $\mathrm{Ca}$ content $\mathrm{x}$, it could be positive and negative depending on these parameters [26]. This means that $\mathrm{La}_{1-\mathrm{x}} \mathrm{Ca}_{\mathrm{x}} \mathrm{VO}_{3}$ films have both electron- and hole-type carriers and the dominant carrier represents the polarity of Seebeck coefficient. In particular, the strong strain of $\mathrm{LaVO}_{3}$ film on a STO may cause its large negative Seebeck coefficient opposite to the reported data of bulk samples [26].

Another work was done to change the valence of vanadium ion from $3+$ to $2+$ by doping $\mathrm{Ce}$ ion into $\mathrm{LaVO}_{3}$. Fig. 6 shows the TE properties of $\mathrm{La}_{1-\mathrm{x}} \mathrm{Ce}_{\mathrm{x}} \mathrm{VO}_{3}(0 \leq \mathrm{x} \leq 1)$ composition-spread films grown at $800^{\circ} \mathrm{C}$. There were little change of TE properties of $\mathrm{La}_{1-\mathrm{x}} \mathrm{Ce}_{\mathrm{x}} \mathrm{VO}_{3}$ films in the range of $0 \leq \mathrm{x} \leq 1$. 


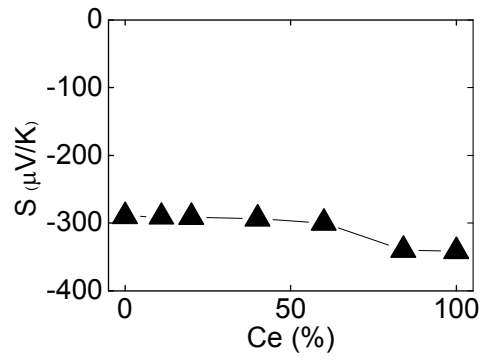

(a)

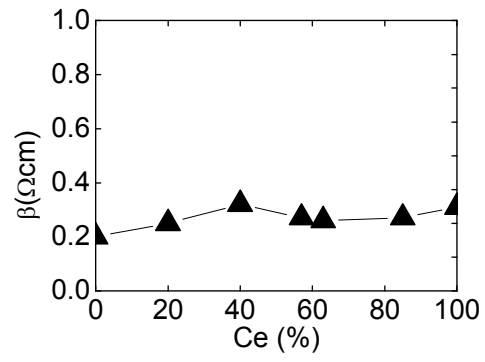

(b)

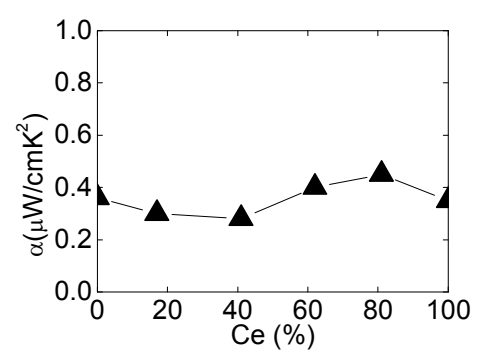

(c)

Fig. 6. TE properties of La1-xCexVO3 $(0 \leq x \leq 1)$ composition-spread films. (a) Seebeck coefficient :S (b)resistivity: $\rho$ (c) power factorpower factor $: \alpha(=S 2 / \rho)$

The Seebeck coefficient of $\mathrm{La}_{1-\mathrm{x}} \mathrm{Ca}_{\mathrm{x}} \mathrm{VO}_{3}$ close to $\mathrm{CaVO}_{3}(0.6 \leq \mathrm{x} \leq 1.0)$ was reported to be sensitive to the temperature and $\mathrm{Ca}$ content $\mathrm{x}$, it could be positive and negative depending on these parameters [26]. This means that $\mathrm{La}_{1-\mathrm{x}} \mathrm{Ca}_{\mathrm{x}} \mathrm{VO}_{3}$ films have both electron- and hole-type carriers and the dominant carrier represents the polarity of Seebeck coefficient. In particular, the strong strain of $\mathrm{LaVO}_{3}$ film on a STO may cause its large negative Seebeck coefficient opposite to the reported data of bulk samples [26].

Another work was done to change the valence of vanadium ion from $3+$ to $2+$ by doping $\mathrm{Ce}$ ion into $\mathrm{LaVO}_{3}$. Fig. 6 shows the TE properties of $\mathrm{La}_{1-\mathrm{x}} \mathrm{Ce}_{\mathrm{x}} \mathrm{VO}_{3}(0 \leq \mathrm{x} \leq 1)$ composition-spread films grown at $800^{\circ} \mathrm{C}$. There were little change of TE properties of $\mathrm{La}_{1-\mathrm{x}} \mathrm{Ce}_{\mathrm{x}} \mathrm{VO}_{3}$ films in the range of $0 \leq \mathrm{x} \leq 1$.

Fig.7 shows the XPS spectrums of (a) La ion of $\mathrm{LaVO}_{3}$ side and (b) $\mathrm{Ce}$ of $\mathrm{CeVO}_{3}$ side. In the system, Ce ion takes $3+$ although $\mathrm{Ce}^{4+}$ is stable in theory. The reason may be that the size of $\mathrm{Ce}^{3+}$ ion is similar to that of $\mathrm{La}^{3+}$ ion, so Ce takes $3+$ easily in $\mathrm{LaVO}_{3}$.

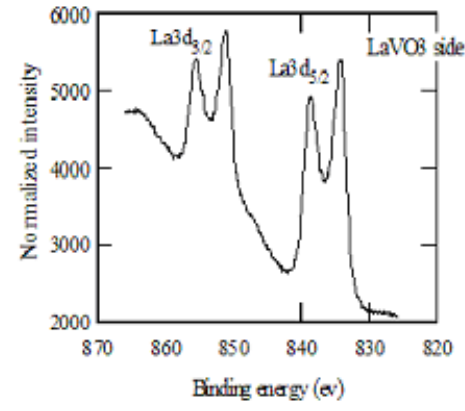

(a)

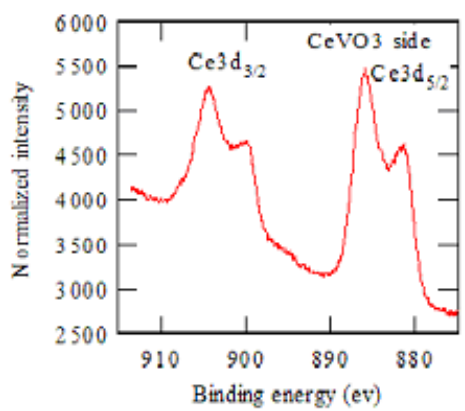

(b)

Fig.7. XPS spectrums of (a) $\mathrm{La}$ ion of $\mathrm{LaVO}_{3}$ side and (b) $\mathrm{Ce}$ of $\mathrm{CeVO}_{3}$ side

\section{Conclusion}

$\mathrm{La}_{1-\mathrm{x}} \mathrm{Ca}_{\mathrm{x}} \mathrm{VO}_{3}$ composition-spread films were fabricated by combinatorial pulsed laser deposition. TE properties of $\mathrm{La}_{1-\mathrm{x}} \mathrm{Ca}_{\mathrm{x}} \mathrm{VO}_{3}$ composition-spread films were evaluated by the multi-channel thermoelectric measurement system. Growth conditions of $\mathrm{LaVO}_{3}$ films were optimized. Good crystallinity of $\mathrm{LaVO}_{3}$ film was obtained at $800^{\circ} \mathrm{C}$, and the power factor of $0.6 \mu \mathrm{W} / \mathrm{cm} \mathrm{K}^{2}$ was achieved. The effects of oxygen content and the substitutions of $\mathrm{Ca}$ and $\mathrm{Ce}$ ions on TE properties of were also analysed respectively. Large TE properties in vanadium oxide system can be expected with the change of vanadium ion valence from $3+$ to $2+$. In La1-xCexVO3 $(0 \leq x \leq 1)$ system, Ce ion takes $3+$ although $\mathrm{Ce}^{4+}$ is stable in theory. 


\section{Acknowledgements}

Authors thank Prof. H.Koinuma and Dr.K.Itaka gratefully for their advice and help, and the support of the National Science Foundation of China (50674033) and the Fundamental Research Funds for the Central Universities (N100409003) for further research work is also acknowledged.

\section{Reference}

[1] M.J. Plunkett, J.A. Ellman, Sci. Am. 276 (1997) 68.

[2] H. Koinuma, H.N. Aiyer, Y. Matsumoto, Sci. Tech. Advan. Mater. 1(2000) 1-10.

[3]X.D. Xiang, X.Sun, G. Briceno, Y. Lou, K. Wang, H. Chang, W.G.Wallac-Freedman, S. Chen, P.G. Schultz, Science 268 (1995) 1738.

[4]K.Fujimoto, K.Onoda, M.Sato, H.Matsuo, Mater. Sci. Eng. A 475(2008)52

[5] R.Lobel, S.Thienhaus, A.Savan, A.Ludwig, Mater. Sci. Eng. A 481-482(2008)151

[6] U.S.Joshi, K.Itaka, Y.Matsumoto, H.Koinuma, Joural of.Magnetism and Magnetic Marerials, 321(2009)3595

[7] C.B. Satterthwaite Jr., R.W. Ure, Phys. Rev. 108 (1957) 1164-1170.

[8] D.M. Rowe, V.S. Shukla, J. Appl. Phys. 52 (1981) 7421-7426.

[9] J.P. Dismukes, L. Ekstrom, E.F. Steigmeier, I. Kuman, D.S. Beers,J. Appl. Phys. 35 (1964) 2899.

[10] I. Terasaki, Y. sasago, K. Uchionkura, Phys. Rev. B 56 (1997) R12685-R12687.

[11] Y. Ando, N. Miyamoto, K. Segawa, T. Kawata, I. Terasaki, Phys. Rev.B 60 (1999) 1058010583.

[12]Xuebin Zhu, Yuping Sun, Hechang Lei, J.Appl.Phys.102(2007)103519

[13]T.Sun, J.Ma, Q.Y.Yan, Journal of CrystalGrowth 311(2009)4123

[14]H.Ohta, K.Sugiura, K. Koumoto, Inorg. Chem,47(2008)8429

[15]S.Wang, M.Chen, L.He, J.Phys.D: Appl.Phys.42(2009)045410

[16] W. Koshibae, K. Tsutsui, S. Maekawa, Phys. Rev. B 62 (2000) 6869.

[17] V.G. Zubkov, et al., Sov. Phys. Solid State 15 (1973) 1079.

[18] A.V. Mahajan, D.C. Johnston, D.R. Torgeson, F. Borsa, Phys. Rev. B 46 (1992) 1096610972.

[19] F. Inaba, T. Arima, T. Ishikawa, T. Katsufuji, Y. Tokura, Phys. Rev. B 52 (1995) R2221R2224.

[20] P. Bordet, C. Chaillout, M. Marezio, Q. Huang, A. Santoro, S-W.Cheong, HTakagi, C.S. Oglesby, B. Batlogg, J. Solid, State Chem.106 (1993) 253-270.

[21] M. Kestigian, J.G. Dickinson, R. Ward, J. Am. Chem. Soc. 79 (1957) 5598.

[22] T. Fukumura, M. Ohtani, M. Kawasaki, Y. Okimoto, T. Kageyama, T.Koida, T. Hasegawa, Y. Tokura, H. Koinuma, Appl. Phys. Lett. 77 (2000) 3426-3428.

[23] K. Omote, T. Kikuchi, J. Harada, M. Kawasaki, A. Ohtomo, M.Ohtani, T. Ohnishi, D. Komiyama, H. Koinuma, Proc. SPIE 3941(2000) 84-91.

[24] K. Itaka, H. Minami, H. Kawaji, Q. Wang, J. Nishii, M. Kawasaki, H.Koinuma, J. Therm. Anal. Cal. 69 (2002) 1051-1058.

[25] M. Imada, A. Fujimori, Y. Tokura, Rev. Mod. Phys. 70 (1998)1039-1263.

[26] H.C. Nguyen, J.B. Goodenough, Phys. Rev. B 52 (1995)8776-8787. 